\title{
Cost analysis of materials used in Class III, IV and V composite resin restorations
}

\author{
Eduardo Hebling', Rodolfo Luís Gonçalves², Dagmar de Paula Queluz ${ }^{1}$
}

${ }^{1}$ Department of Community Dentistry, Piracicaba Dental School, University of Campinas, Piracicaba, SP, Brazil

${ }^{2}$ Dentist of the Brazilian Federal Court, Rio de Janeiro, RJ, Brazil

Received for publication: August 02, 2013 Accepted: November 25, 2013

Correspondence to: Eduardo Hebling

Faculdade de Odontologia de Piracicaba Universidade Estadual de Campinas Avenida Limeira, 901, CEP: 13414-903 Areião, Piracicaba, SP, Brasil Phone: +55 1921065280

Fax: +551921065218 E-mail: hebling@fop.unicamp.br

\begin{abstract}
Aim: To assess the total cost of direct and indirect materials used in Class III, IV and V composite resin direct restorations. Methods: The calculation of costs was based on the method of variable costing system. A list of the materials was obtained by a panel of experts and based on the excellence standards established in the literature for dental team treatment. The cost considered for each material was obtained from an average of the costs found in the regional supplier market (US\$1.0=R\$2.12). The repetitions were obtained from Class III, IV and V cavities in artificial premanufactured teeth. The cavities were classified as shallow, medium and deep. The materials were quantified for each type of preparation. Seven brands of composite resins were used and weighed on a precision scale after their insertion in each cavity. The data were analyzed by descriptive statistics and non-parametric Friedman's test $(\alpha=0.05)$. Results: The mean costs were US\$7.96 (R\$16.88) for Class III restoration, US\$8.13 (R\$17.24) for Class IV, and US\$7.84 $(\mathrm{R} \$ 16.62)$ for Class $\mathrm{V}$. There was statistically significant difference in cost between the types of cavities and depth classification. The small cost difference among the different resin brands resulted in no statistically significant differences in the total cost of the restorations. Conclusions: The costs obtained in this survey may be used in the calculation of the final cost of restorative procedures, helping in the management of public or private dental care services.
\end{abstract}

Keywords: dentistry, costs and cost analysis, dental materials, composite resins.

\section{Introduction}

Composite resins are commonly used materials in direct dental restorations. The similarity of the original color of the teeth, afforded by the use of composite resins, allows the maintenance and restoration of the aesthetics of the smile, increasing the preference for this restorative material in both anterior and posterior teeth by professionals and patients ${ }^{1}$.

The materials used in dental procedures can be classified into direct and indirect materials ${ }^{2}$. Drills, matrix strips, wedges and composite resin are examples of direct materials used in a restorative procedure. Disinfecting solutions, gloves, cap and glasses are examples of used indirect materials.

Dental care services in both private and public sectors should be managed with the same principles applied to a commercial enterprise. Although fixed costs can differ from one place to another, some direct variable costs related to the implementation of the service have their values established by some criteria that do not depend exclusively on the operator or manager of the service, such as the cost of dental materials. The price determined by the manufacturers and suppliers 
of dental products, the amount of material required by cavity size, and the type of these materials established by clinical and scientific evidence, are examples of these criteria ${ }^{3}$.

A costing system consists in determining a criterion by which the costs are apportioned for the production. According the system employed, certain costs may or may not be part of the production costs ${ }^{4,5}$. In the variable costing system is appropriate to services only the variable costs of production, both direct and indirect ${ }^{5}$. The cost of materials is part of the calculation of the value of the fees for direct dental restorations. Knowing the cost of the materials used can help planning of actions to manage the dental care services and determination of dental restoration fees ${ }^{3,5-7}$.

Despite the continuous need for less costly dental treatments ${ }^{8}$ and standardization of dental procedures based on scientific evidence ${ }^{9}$, there is remarkably scarce information on the costs of different restorative materials and their use ${ }^{10}$. The few studies available on this subject are mostly based on estimates of longevity of the restoration, in performance of retreatments in the medium and long term, and on their relative cost and benefits and effectiveness ${ }^{11}$. As up to date there are no publications that calculate the costs for direct and indirect materials used for direct dental restorations. Thus, this study was designed to determine the total cost of direct and indirect materials used in Class III, IV and V cavities. An specific aim was to compare the mean cost of direct and indirect materials used in those types of cavity with different sizes. The null hypothesis was that there is no difference in mean cost values among these variables.

\section{Material and methods}

This experimental study was developed at the Piracicaba Dental School, University of Campinas, Piracicaba, Brazil in 2012. The calculation of costs was based on the method of variable costing system ${ }^{5}$.

The list of materials was obtained through consultation by a panel of experts and based on the excellence standards established in the literature for dental team treatment, applying restorative techniques with efficiency and productivity ${ }^{2}$, and respecting the biosecurity of the patient and the dental team $^{12,15}$, the use of materials ${ }^{16,17}$ and the ethical principles ${ }^{18}$. This panel of experts was formed by 10 dentists with over 20 years of experience (4 restorative dentistry clinical specialists, 2 general dentists, 3 Restorative Dentistry professors and 1 Dental Materials professor) and 2 dental hygiene technicians with 10 years of experience. A list of materials to be used was prepared by the authors. The referees reviewed each item according to the Likert scale ${ }^{19}$ and attributed the following classifications: 1) strongly disagree; 2) disagree; 3) neither agree nor disagree; 4) agree; 5) strongly agree. The referees were also given the possibility of including a suggestion. The materials and quantities classified with scores 4 and 5 by the referees were maintained in the final list of materials.

The costs of the materials were obtained from an average of the cost found in the supplier market of the administrative region of Campinas-SP, Brazil, in three different resellers.
The obtained costs in local currency (Real) were converted to American dollars (US\$1.00 $=\mathrm{R} \$ 2.12$ ). This cost was adjusted according to the amount of material to be used. For the non-disposable materials, the cost was adjusted considering their mean use life.

The amount of material was stipulated by simulating a clinical restorative procedure. This quantity was measured with the use of a graduated measuring cylinder, for liquid materials, and precision digital scale (Model AB-S; Mettler Toledo ${ }^{\circledR}$,Barueri, SP, Brazil,) with reading range of $0.01 \mathrm{mg}$ to $0.1 \mathrm{mg}$, weighting capacity from $51 \mathrm{~g}$ to $320 \mathrm{~g}$, for solid materials.

The repetitions were obtained from Classes III, IV, and V cavities preparations in artificial permanent pre-manufactured teeth. Each type of cavity was classified in relation to the preestablished depth as shallow, medium and deep, totalizing 9 anterior artificial teeth. The depth classification was established by the authors in the artificial teeth, which are supplied by the manufacturer with cavities prepared according to the currently recommended conservative techniques ${ }^{16,17}$.

The list of materials was set up considering the dental care performed by the dental team (operator and auxiliary), following the biosecurity principles and the currently recommended conservative restorative techniques based on scientific evidence ${ }^{15-17}$. The operative and restorative procedures were standardized as follows: specific diamond drills $^{20}$ were sterilized before use and changed after being used in 10 patients $^{21,22}$; no liner was used; absolute isolation was provided; use of condensation composite resin; an incremental placement technique was employed for the restorative materials; occlusal adjustment, finishing and polishing were performed with carbon paper and specific tips and sandpaper discs and strips ${ }^{16,17}$.

The materials were classified into 7 different groups and for each one were established the following standardization criteria ${ }^{23}$ :

- Group 1: Materials used for the maintenance and cleaning of equipment.

- Dental operating room equipment containing: 1) two ultra-speed air handpieces, a set of slow-speed air handpiece micro-motor with contra angle and three-way syringe; 2) an auxiliary unit containing one spittoon, vacuum system with saliva and blood suction hoses, one three-way syringe and one light-curing device; 3) a chair with the seat and back without seams or buttons, drive command by feet and arm support on both sides; 4) a monofocal spotlight with single cable; 5) stools, one for the operator and one for the auxiliary; 6) mobile auxiliary table, size $60 \times 50 \mathrm{~cm}$;

- Lubrication of high and slow-speed handpieces: two sprays of lubricating oil into the drive air line; lubricant oil recommended by the manufacturer for each four hours of use;

- Disinfection: use of two gauzes and disinfectant solution. Sterilization: use of sterilization packaging following the manufacturer's guidelines ${ }^{12,13}$.

- Group 2: Materials used as disposable personal protective equipment (PPE) and for the biosecurity of the team and the patient.

- Use of PPE and washing of hands by helping to perform 
the disinfection of dental equipment; use of PPE and washing of hands by the operator and the auxiliary to the clinical care; use of protective barriers for the equipment; protective barriers and eyeglass for the patient; use of preoperative mouthwash with antiseptic solution by the patient.

- Group 3: Materials used for the sterilization of instruments.

- Sterilization in autoclave with polypropylene thermoplastic seal packaging.

- Group 4: Materials for anesthesia

- Local anesthesia; topical anesthetic gel, applied with cotton ball; solution of lidocaine $2 \%$ with epinephrine 1:100,000 (two tubes per patient); long needle.

- Group 5: Materials for absolute isolation and cavity preparation.

- Use of sterilized and reused drills for up to 10 patients $^{21,22}$;

- Number of drills: two types of high-speed diamond drills; low-speed carbide drills ${ }^{20}$;

- Use of restorative instruments (packaged in drilled holster), metal tray, rubber dam, template, punch, clamp forceps, isolation arc, scissors, ivory clamps (packaged in drilled holster with separations), drills (wrapped in small drilled holster for eight drills).

- Group 6: Materials for tooth restoration

- Materials were sub-classified in common use materials for Classes III, IV, and V cavities, and specific materials for Classes III and IV cavities (such as anatomic wooden wedges);

- Adper Single Bond 2 (3M ESPE, Sumaré, SP, Brazil) adhesive system for all types of resin;

- Composite resins brands: Llis (FGM, Joinvile, SC, Brazil); Fill Magic (Vigodent, Rio de Janeiro, RJ, Brazil); Charisma (Heraeus-Kulzer, São Paulo, SP, Brazil); Prisma APH (Dentsply, Petrópolis, RJ, Brazil); Z350 (3M Espe,); Herculite XRV (Kerr, São Paulo, SP Brazil); Tetric N-Ceram (Ivoclar Vivodent, São Paulo, SP, Brazil).

- Group 7: Materials for finishing and polishing of the tooth restoration:

- Assembled tips: use of materials in up to 10 patients ${ }^{21,22}$;

- Carbon paper and finishing and polishing dises and trips: single use, disposable.

The main goal of the present study was to determine the cost of the materials in Group 6. In this group, the materials were quantified for each type of preparation and depth classification. The amount of each material determined the final cost individually. The simulation of material use was performed by calibrated professionals (Kappa $>0.85$ ). The calibration process consisted by one hour of theory discussion, four hours of practical training, including both repetitions of insertion and weighing and intra-examiner differences.

The amount of adhesive was measured in drops, predetermined by the panel of experts. The amount of resin used was determined after its insertion in the artificial tooth of each type of preparation and cavity depths, following the realization of a pre-sculpture of the tooth anatomy, removing the excesses and the weighing the artificial tooth with the material, discounting the tooth weight. The final value of the cost of the direct and indirect materials was calculated by the sum of the individual costs of each used material.

The independent variables studied in this study were: composite resin trade mark (seven types); cavity preparation (Classes III, IV and V) and depth of the cavity preparation (shallow, medium and deep). The data of mean cost of direct and indirect materials used in Classes III, IV and V composite resin dental restorations were used to analyze comparatively all the independent studied variables. The dependent variable was the total cost of the used direct and indirect materials.

Descriptive analysis of the mean cost of direct and indirect materials used in Classes III, IV and V composite resin restorations were performed. Mean values found for the seven groups of materials were considered. For each evaluated material it was determined the amount of material required, the amount of material per package, the average price of materials per package and the adjusted price for the quantity required for the achievement of the restorative procedure.

Data were assessed by the non-parametric Friedman's test for dependent variable. This test was applied to two factors, the first factor was a fixed independent variable and the second factor were the blocks of each combination of the other two independent variables. When the Friedman's test indicated significant differences between the groups, the Siegel-Castellan test of multiple comparisons was applied. A 5\% significance level was used to check which groups were statistically different.

\section{Results}

The values of the cost of the direct and indirect materials included in groups $1,2,3,4,5$ and 7 relating to materials for biosecurity, for local anesthesia, for absolute isolation and for cavity preparation were presented in a previous study ${ }^{23}$. The mean total cost found for the biosecurity materials (Groups 1 to 3) was of US\$4.18 ( $\$ \$ 8.86)$. Out of this amount, the materials of Group 2, which correspond to PPE disposable materials and to the biosecurity for the dental team and the patient, represented $56.72 \%$ and, in Groups 1 and 3 corresponded to $6.89 \%$ and $36.39 \%$, respectively. The mean total cost found for the materials used for local anesthesia (Group 4) was of US\$1.01 (R\$2.14), the anesthetic represented $90.23 \%$ of that value, and the topical anesthetic and the needle corresponded to $1.4 \%$ and $8.37 \%$, respectively.

Materials used for absolute isolation and cavity preparation (Group 5) showed mean a total value of US\$1.0 ( $\mathrm{R} \$ 2.12)$, the materials used to cavity preparation represented $67.30 \%$ and those for absolute isolation corresponded to $32.7 \%$ of this value. The distribution of costs adjusted for these materials showed that the cost of the drills of low and high-speed represented the highest found value, corresponding to $64 \%$ of the total cost for this group. The cost of the rubber dam, used in absolute isolation was responsible for $26 \%$ of the mean total value of this group, which corresponds to the mean value of US\$0.26 $(\mathrm{R} \$ 0.55)^{23}$.

Materials used for dental finishing and polishing (Group 7) showed mean total value of US\$1.23 (R\$2.61). The distribution of costs adjusted for materials showed that the 
costs of carbon paper and assembled part of silicone for finishing corresponded to $74.23 \%$ of the mean total value of this group $^{23}$.

The calculation of the weights (in grams) of the evaluated composite resins is shown in Table 1 . The mean weight found for class III was $0.027( \pm 0.015) \mathrm{g}$, for class IV was 0.052 $( \pm 0.040) \mathrm{g}$ and for class $\mathrm{V}$ was $0.021( \pm 0.007) \mathrm{g}$. The calculation of the adjusted value (in US\$) by gram from evaluated composite resins was shown in Table 2. The mean adjusted value found was US\$6.77 ( $\mathrm{R} \$ 14.35)$. The calculation of the cost (in US\$) of the evaluated composite resins according the studied cavity preparation is shown in Table 3. Mean values found for class III were US\$0.18 \pm 0.10 (R\$0.38), for class IV was US\$0.35 \pm 0.26 (R\$0.74), and for class V was US\$0.14 $\pm 0.05(\mathrm{R} \$ 0.30)$.

The calculation of the cost (in US\$) of the materials used for tooth restoration according the type of cavity preparation (Group 6) was shown in Table 4. Adjusted cost found for class III was US\$0.55 (R\$1.17), for class IV was US\$0.72 (R\$1.53), and for class V was US\$0.43 (R\$0.91). The differences found are due to the greater amount of resin used for class IV than for classes III and V, and to the use of polyester matrix and wedges for classes III and IV.
Costs (in US\$) of the direct and indirect materials used in Class III, IV and V composite resin dental restoration were shown in Table 5. The mean total cost found for class III was US\$7.96 (16.88), for class IV was US\$8.13 (R\$17.24), and for class V was US\$7.84 (16.62). There were no significant differences in total cost of restorative materials between the types of cavity.

Figure 1 shows the non-parametric statistical data. The slot A shows the difference between the total costs of the materials to the types of studied composite resin. Charisma, Prisma APH, Z350, and Tetric N-Ceram composite resin trade marks showed higher total mean cost than Llis, Fill Magic, and Herculite XRV composite resin brands. There were statistically significant differences between Llis and Fill Magic to Z350 and Charisma composite resins; between Magic Fill, Charisma, Prisma APH, Z350 to Tetric N-Ceram composite resins; and between Herculite XRV and Z350 to Charisma composite resins. The slot $\mathrm{B}$ shows the difference between the total costs of the materials to the types of cavity preparation. There were statistically significant differences of class III and IV to class $\mathrm{V}$. The slot $\mathrm{C}$ shows the difference between the total costs of the materials to the types of depth classification. There was statistically significant difference between the types of depth classification of the cavity preparation.

Table 1. Calculation of weight (in grams) of the composite resins according the type of cavity.

\begin{tabular}{|c|c|c|c|c|c|c|c|c|c|}
\hline \multirow[b]{2}{*}{ Class } & \multirow[b]{2}{*}{ Depth } & \multicolumn{7}{|c|}{ Evaluated composite resin trade mark } & \multirow{2}{*}{$\begin{array}{l}\text { Mean } \\
( \pm S D)\end{array}$} \\
\hline & & Llis & $\begin{array}{c}\text { Fill } \\
\text { Magic }\end{array}$ & Charisma & $\begin{array}{c}\text { Prisma } \\
\text { Aph }\end{array}$ & Z350 & $\begin{array}{c}\text { Herculite } \\
\text { Xrv }\end{array}$ & $\begin{array}{l}\text { Tetric N- } \\
\text { Ceram }\end{array}$ & \\
\hline \multirow{4}{*}{ CLASS III } & Shallow & 0.0124 & 0.0121 & 0.0136 & 0.0122 & 0.0104 & 0.0123 & 0.0111 & $\begin{array}{l}0.0120 \\
(0.001)\end{array}$ \\
\hline & Medium & 0.0258 & 0.0251 & 0.0243 & 0.0255 & 0.0228 & 0.0256 & 0.0263 & $\begin{array}{l}0.0251 \\
(0.001)\end{array}$ \\
\hline & Deep & 0.0453 & 0.0417 & 0.0420 & 0.0422 & 0.0379 & 0.0454 & 0.0462 & $\begin{array}{l}0.0430 \\
(0.003)\end{array}$ \\
\hline & $\begin{array}{l}\text { Mean } \\
( \pm \mathrm{SD})\end{array}$ & $\begin{array}{l}0.0278 \\
(0.017)\end{array}$ & $\begin{array}{l}0.0263 \\
(0.015)\end{array}$ & $\begin{array}{l}0.0266 \\
(0.014)\end{array}$ & $\begin{array}{l}0.0266 \\
(0.015)\end{array}$ & $\begin{array}{l}0.0237 \\
(0.014)\end{array}$ & $\begin{array}{l}0.0278 \\
(0.017)\end{array}$ & $\begin{array}{l}0.0279 \\
(0.018)\end{array}$ & $\begin{array}{l}0.0267 \\
(0.015)\end{array}$ \\
\hline \multirow{4}{*}{ CLASS IV } & Shallow & 0.0219 & 0.0211 & 0.0239 & 0.026 & 0.0200 & 0.0223 & 0.0239 & $\begin{array}{l}0.0227 \\
(0.002)\end{array}$ \\
\hline & Medium & 0.0394 & 0.0362 & 0.0371 & 0.0359 & 0.0327 & 0.0333 & 0.0351 & $\begin{array}{l}0.0357 \\
(0.002)\end{array}$ \\
\hline & Deep & 0.1054 & 0.1010 & 0.0926 & 0.0965 & 0.0904 & 0.0965 & 0.1004 & $\begin{array}{l}0.0975 \\
(0.005)\end{array}$ \\
\hline & $\begin{array}{l}\text { Mean } \\
( \pm \mathrm{SD})\end{array}$ & $\begin{array}{l}0.0556 \\
(0.044)\end{array}$ & $\begin{array}{l}0.0528 \\
(0.042)\end{array}$ & $\begin{array}{c}0.0512 \\
(0.037)\end{array}$ & $\begin{array}{l}0.0528 \\
(0.038)\end{array}$ & $\begin{array}{l}0.0477 \\
(0.038)\end{array}$ & $\begin{array}{l}0.0507 \\
(0.040)\end{array}$ & $\begin{array}{l}0.0531 \\
(0.041)\end{array}$ & $\begin{array}{l}0.0520 \\
(0.040)\end{array}$ \\
\hline \multirow{5}{*}{ CLASS V } & Shallow & 0.0158 & 0.0163 & 0.0166 & 0.0154 & 0.014 & 0.0155 & 0.0167 & $\begin{array}{l}0.0158 \\
(0.001)\end{array}$ \\
\hline & Medium & 0.0195 & 0.0188 & 0.0196 & 0.0198 & 0.0174 & 0.018 & 0.0218 & $\begin{array}{l}0.0193 \\
(0.001)\end{array}$ \\
\hline & Deep & 0.0291 & 0.0293 & 0.0286 & 0.031 & 0.0262 & 0.0283 & 0.0312 & $\begin{array}{l}0.0291 \\
(0.002)\end{array}$ \\
\hline & Mean & 0.0215 & 0.0215 & 0.0216 & 0.0221 & 0.0192 & 0.0206 & 0.0232 & 0.0214 \\
\hline & ( \pm SD) & $(0.007)$ & $(0.007)$ & $(0.006)$ & $(0.008)$ & $(0.006)$ & $(0.007)$ & $(0.007)$ & $(0.007)$ \\
\hline
\end{tabular}


Table 2. Calculation of the adjusted value (in US\$) per gram of the evaluated composite resins.

\begin{tabular}{l|c|c|c|c|c}
\hline $\begin{array}{c}\text { Evaluated composite resin } \\
\text { brand (weight in grams/tube) }\end{array}$ & $\begin{array}{c}\text { Supplier } \\
\mathbf{1}\end{array}$ & $\begin{array}{c}\text { Supplier } \\
\mathbf{2}\end{array}$ & $\begin{array}{c}\text { Supplier } \\
\mathbf{3}\end{array}$ & Mean & $\begin{array}{c}\text { Adjusted value by } \\
\text { gram }\end{array}$ \\
\hline Llis (4 g) & 10.24 & 10.80 & 10.59 & 10.54 & 2.635 \\
\hline Fill Magic (4g) & 10.24 & 10.80 & 10.59 & 10.54 & 2.635 \\
\hline Charisma (4g) & 37.99 & 38.30 & 38.77 & 38.36 & 9.590 \\
\hline Prisma Aph (4g) & 33.96 & 34.53 & 35.14 & 34.54 & 8.635 \\
\hline Z350 (4g) & 42.45 & 44.06 & 46.93 & 44.48 & 11.120 \\
\hline Herculite XRV (5g) & 21.23 & 21.75 & 22.12 & 21.70 & 4.340 \\
\hline Tetric N-Ceram (3.5g) & 28.58 & 28.89 & 31.21 & 29.56 & 8.450 \\
\hline Mean & $\mathbf{2 6 . 3 8}$ & $\mathbf{2 7 . 0 2}$ & $\mathbf{2 7 . 9 1}$ & $\mathbf{2 7 . 1 0}$ & $\mathbf{6 . 7 7 2}$ \\
\hline
\end{tabular}

Table 3. Calculation of the cost (in US\$) of the composite resins according the type of cavity.

\begin{tabular}{|c|c|c|c|c|c|c|c|c|c|}
\hline \multirow[b]{2}{*}{ Class } & \multirow[b]{2}{*}{ Depth } & \multicolumn{7}{|c|}{ Evaluated composite resin brand } & \multirow{2}{*}{$\begin{array}{c}\text { Mean } \\
( \pm S D)\end{array}$} \\
\hline & & Llis & Fill Magic & Charisma & $\begin{array}{c}\text { Prisma } \\
\text { Aph }\end{array}$ & Z350 & $\begin{array}{c}\text { Herculite } \\
\text { Xrv }\end{array}$ & $\begin{array}{c}\text { Tetric N- } \\
\text { Ceram }\end{array}$ & \\
\hline \multirow{4}{*}{$\begin{array}{r}\text { CLASS } \\
\text { III }\end{array}$} & Shallow & 0.033 & 0.032 & 0.130 & 0.105 & 0.116 & 0.053 & 0.094 & $\begin{array}{c}0.080 \\
(0.041)\end{array}$ \\
\hline & Medium & 0.068 & 0.066 & 0.233 & 0.220 & 0.254 & 0.111 & 0.222 & $\begin{array}{c}0.168 \\
(0.083)\end{array}$ \\
\hline & Deep & 0.119 & 0.110 & 0.403 & 0.364 & 0.421 & 0.197 & 0.390 & $\begin{array}{c}0.286 \\
(0.139)\end{array}$ \\
\hline & $\begin{array}{l}\text { Mean } \\
( \pm \mathrm{SD})\end{array}$ & $\begin{array}{c}0.073 \\
(0.042)\end{array}$ & $\begin{array}{c}0.069 \\
(0.039)\end{array}$ & $\begin{array}{r}0.255 \\
(0.137)\end{array}$ & $\begin{array}{c}0.230 \\
(0.129)\end{array}$ & \begin{tabular}{|c|}
0.264 \\
$(0.152)$
\end{tabular} & $\begin{array}{r}0.120 \\
(0.073)\end{array}$ & $\begin{array}{c}0.235 \\
(0.148)\end{array}$ & $\begin{array}{c}0.178 \\
(0.103)\end{array}$ \\
\hline \multirow{4}{*}{$\begin{array}{r}\text { CLASS } \\
\text { IV }\end{array}$} & Shallow & 0.058 & 0.056 & 0.229 & 0.225 & 0.222 & 0.097 & 0.202 & $\begin{array}{c}0.155 \\
(0.081)\end{array}$ \\
\hline & Medium & 0.104 & 0.095 & 0.356 & 0.310 & 0.364 & 0.145 & 0.296 & $\begin{array}{c}0.239 \\
(0.119)\end{array}$ \\
\hline & Deep & 0.278 & 0.266 & 0.888 & 0.833 & 1.005 & 0.419 & 0.848 & $\begin{array}{c}0.648 \\
(0.315)\end{array}$ \\
\hline & $\begin{array}{l}\text { Mean } \\
( \pm \mathrm{SD})\end{array}$ & $\begin{array}{c}0.146 \\
(0.116)\end{array}$ & $\begin{array}{c}0.139 \\
(0.112)\end{array}$ & $\begin{array}{c}0.491 \\
(0.350)\end{array}$ & $\begin{array}{c}0.456 \\
(0.329)\end{array}$ & \begin{tabular}{|c|}
0.530 \\
$(0.417)$
\end{tabular} & $\begin{array}{r}0.220 \\
(0.174)\end{array}$ & $\begin{array}{c}0.449 \\
(0.349)\end{array}$ & $\begin{array}{c}0.347 \\
(0.264)\end{array}$ \\
\hline \multirow{4}{*}{$\begin{array}{r}\text { CLASS } \\
\mathbf{v}\end{array}$} & Shallow & 0.042 & 0.043 & 0.159 & 0.133 & 0.156 & 0.067 & 0.141 & $\begin{array}{c}0.106 \\
(0.053)\end{array}$ \\
\hline & Medium & 0.051 & 0.050 & 0.188 & 0.171 & 0.193 & 0.078 & 0.184 & $\begin{array}{c}0.131 \\
(0.067)\end{array}$ \\
\hline & Deep & 0.077 & 0.077 & 0.274 & 0.268 & 0.291 & 0.123 & 0.264 & $\begin{array}{c}0.196 \\
(0.099)\end{array}$ \\
\hline & $\begin{array}{l}\text { Mean } \\
( \pm \mathrm{SD})\end{array}$ & $\begin{array}{c}0.057 \\
(0.018)\end{array}$ & $\begin{array}{c}0.057 \\
(0.018)\end{array}$ & $\begin{array}{c}0.207 \\
(0.060)\end{array}$ & $\begin{array}{c}0.191 \\
(0.070)\end{array}$ & $\begin{array}{c}0.214 \\
(0.070)\end{array}$ & $\begin{array}{r}0.089 \\
(0.030)\end{array}$ & $\begin{array}{c}0.196 \\
(0.062)\end{array}$ & $\begin{array}{c}0.144 \\
(0.046)\end{array}$ \\
\hline
\end{tabular}


Table 4: Calculation of the cost (in US\$) of the materials used for dental restoration according the type of cavity (Group 6).

\begin{tabular}{|c|c|c|c|c|}
\hline Material & $\begin{array}{l}\text { Quantity } \\
\text { required }\end{array}$ & $\begin{array}{c}\text { Quantity per } \\
\text { pack }\end{array}$ & $\begin{array}{c}\text { Mean of cost per } \\
\text { pack }\end{array}$ & $\begin{array}{c}\text { Adjusted } \\
\text { value }\end{array}$ \\
\hline \multicolumn{5}{|l|}{ CLASS III } \\
\hline Microbrush $^{1}$ & 1 & $100 u$ & 5.93 & 0.06 \\
\hline $37 \%$ phosphoric acid etching gel & $0.05 \mathrm{~g}$ & $3 g$ & 3.02 & 0.05 \\
\hline Bonding liquid & $0.04 \mathrm{~g}$ & $6 g$ & 27.20 & 0.18 \\
\hline Composite resin² & $0.027 \mathrm{~g}$ & $4 g$ & 27.10 & 0.18 \\
\hline Polyester Matrix & 1 & $50 u$ & 1.66 & 0.04 \\
\hline Wedges & 1 & $100 u$ & 3.69 & 0.04 \\
\hline \multicolumn{4}{|l|}{ Total (US\$) } & 0.55 \\
\hline \multicolumn{5}{|l|}{ CLASS IV } \\
\hline Microbrush ${ }^{1}$ & 1 & $100 u$ & 5.93 & 0.06 \\
\hline $37 \%$ phosphoric acid etching gel & $0.05 \mathrm{~g}$ & $3 g$ & 3.02 & 0.05 \\
\hline Bonding liquid & $0.04 \mathrm{~g}$ & $6 g$ & 27.20 & 0.18 \\
\hline Composite resin ${ }^{2}$ & $0.052 \mathrm{~g}$ & $4 g$ & 27.10 & 0.35 \\
\hline Polyester Matrix & 1 & $50 u$ & 1.66 & 0.04 \\
\hline Wedges & 1 & $100 u$ & 3.69 & 0.04 \\
\hline \multicolumn{4}{|l|}{ Total (US\$) } & 0.72 \\
\hline \multicolumn{5}{|l|}{ CLASS V } \\
\hline Microbrush ${ }^{1}$ & 1 & 100 & 5.93 & 0.06 \\
\hline $37 \%$ phosphoric acid etching gel & $0.05 \mathrm{~g}$ & $3 \mathrm{~g}$ & 3.02 & 0.05 \\
\hline Bonding liquid & $0.04 \mathrm{~g}$ & $6 \mathrm{~g}$ & 27.20 & 0.18 \\
\hline Composite resin ${ }^{2}$ & $0.021 \mathrm{~g}$ & $4 g$ & 27.10 & 0.14 \\
\hline \multicolumn{4}{|l|}{ Total (US\$) } & 0.43 \\
\hline
\end{tabular}

${ }^{1}$ Microbrush $^{\mathrm{TM}}$ (FGM, KG Sorensen, Brazil).

${ }^{2}$ Composite resin: mean weight of composite resin used in Class III, IV and V (Table 1). Mean of the values of the studied composite resins (Table 3 ).

Table 5. Mean cost of the direct and indirect materials used in Class III, IV and V composite resin dental restoration in US\$ and percent value (\%).

\begin{tabular}{l|l|l|l|l|l|c}
\hline \multicolumn{1}{c|}{ Group of Materials } & Class III & \% & Class IV & $\%$ & Class V & $\%$ \\
\hline Maintenance and cleaning (Group 1) & 0.288 & 3.6 & 0.288 & 3.5 & 0.288 & 3.7 \\
\hline Biosecurity (Group 2) & 2.371 & 29.8 & 2.371 & 29.2 & 2.371 & 30.2 \\
\hline Sterilization (Group 3) & 1.519 & 19.1 & 1.519 & 18.7 & 1.519 & 19.4 \\
\hline Anesthesia (Group 4) & 1.014 & 12.7 & 1.014 & 12.5 & 1.014 & 12.9 \\
\hline $\begin{array}{l}\text { Absolute isolation and cavity } \\
\text { preparation (Group 5) }\end{array}$ & 0.995 & 12.5 & 0.995 & 12.2 & 0.995 & 12.7 \\
\hline Dental restoration (Group 6) & 0.550 & 6.9 & 0.720 & 8.8 & 0.430 & 5.5 \\
\hline Finishing and Polishing (Group 7) & 1.226 & 15.4 & 1.226 & 15.1 & 1.226 & 15.6 \\
\hline Total & $\mathbf{7 . 9 6 2}$ & $\mathbf{1 0 0}$ & $\mathbf{8 . 1 3 2}$ & $\mathbf{1 0 0}$ & $\mathbf{7 . 8 4 2}$ & $\mathbf{1 0 0}$ \\
\hline
\end{tabular}

1 - Secondary data from Hebling \& Trentin, 2013 (23). 


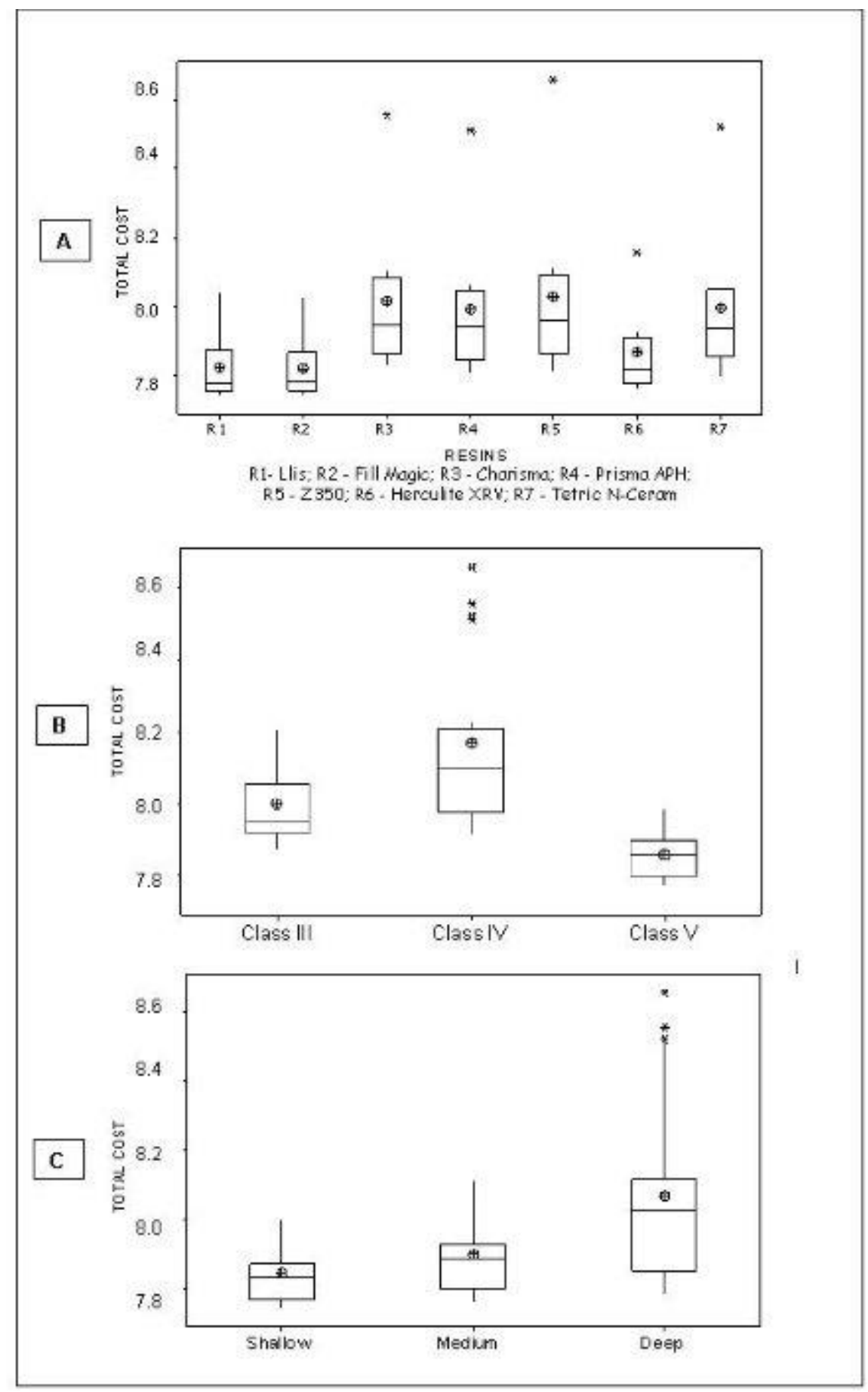

Fig. 1 - Slot-plots of the non-parametric statistical data: A- Difference between the total costs of the materials to types of studied composite resin; B- Difference between the total costs of the materials to types of cavity; C- Difference between the total costs of the materials to types of depth classification.

\section{Discussion}

This is the first study in which the cost analysis of materials used in Classes III, IV, and V composite resin dental restorations has been analyzed in Brazil. To the best of our knowledge, no cost analysis on any aspect has been published in Brazil or worldwide, which makes it difficult to establish comparisons of our results.
The list drawn up by researchers and evaluated by the panel of referees represents an ideal pattern of care, including the requirements for excellence in productivity and quality of restorative procedures. All the biosecurity measures were included, while respecting the ethical and legal precepts ${ }^{12-15}$.

This standard of excellence of care should be observed in all types of dental care services, be they public or private, when performing direct composite resin dental restorations. 
Reduction of excellence of care may result in reduction of the cost of biosecurity. However, the risks to the health of patients and dental team hardly compensates for this reduction. Direct dental restorations are low-risk contamination procedures. Even so, the principles of biosecurity must be respected ${ }^{12-15}$. The use of protection barriers reduces the risk of cross-contamination for both the treated patients and the dental team ${ }^{15}$.

The low total cost of biosecurity in this type of procedure (\$4.18/R $\$ 8.86$ ) is still much lower than the values to be spent to minimize the possible effects of a contamination of the team or the patient by any infectious disease. The risks of inability to work and death of the dental team should also be considered, which may occur even in low-risk procedures, as is in case of tooth restorations. The lack of other Brazilian or international articles on the same subject made it difficult to compare these results.

The economic stability of Brazil, with control of inflation and reduction in the rate of increase in materials' prices, reflects in the present study. There were no statistically significant differences in the total costs of the studied materials among the three evaluated suppliers.

The present study showed that the mean cost of materials for Class III restoration was US\$7.96 (R $\$ 16.88)$, for Class IV it was US\$8.13 (R\$17.24) and for Class V it was US\$7.84 ( $\mathrm{R} \$ 16.62)$. There was a statistically significant difference in cost among Classes III, Class IV and V restoration. The cost of materials for Class IV is higher than for Classes III and V due to the high involvement of the tooth surfaces in the cavity preparation, requiring more restorative material than for the other two types. Although it had a lower cost, the polyester matrix and wedge made the material costs for Classes III and IV to be higher than for Class V. This value does not represent the value of dental care fees to be charged to the patient. The cost of the material is part of the variable costs to be considered in the calculation of the value of dental care fees. For this calculation it must be considered both the fixed and the variable costs associated with the dental care service ${ }^{3-5}$.

Differences in the properties of composite resins have been demonstrated in other studies ${ }^{16,17}$. However, the ultimate goal of achieving a direct restorative procedure is to obtain esthetic and functional results of the tooth, with long-lasting acceptable procedure, and it can be achieved with any type of the commercial brands of resin available on the market. Thus, the small difference in the cost of the different evaluated resins results that there is no significant difference in the final total cost of the used materials. This fact allows that composite resins with better physical and aesthetic characteristics be elected as primary choice.

In 2012, the National Commission of Covenants and Accreditations ${ }^{24}$ established the reference values for dental procedures and stated minimum values of dental fees to be complied with in the private sector. The values suggested for Class III restoration in composite resin type was US $\$ 43.20$ (US\$1.0 = R \$2.12), for Class IV it was US\$61.31 and for Class $\mathrm{V}$ it was US\$40.98. The cost of the materials presented in this study, which represent only one of the items to be considered in the calculation of the fees ${ }^{5}$, corresponded to $18.45 \%$ of the fees for Class III, $13.27 \%$ for Class IV, and $19.15 \%$ for Class V. This fact reinforces the need for constant review of these fees.

In the public sphere, the deployment of oral health funding policy for the municipalities with full management modified the lending forms to health financing. The financial resources are no longer intended for production according to the type of procedure to be performed, but according to the type of oral health program to which the municipality joins, according to the operations per inhabitant and program ${ }^{25}$. In this way, the results of this study cannot be compared with the resources transferred to the municipality. However, managers of dental services, both public and private may use the data of this study as parameters in strategic decision-making from choosing the type of composite resin up to the operability of using absolute isolation.

The use or further development of this methodology for other groups of researchers in different scenarios and countries must be stimulated, thus allowing comparisons of the cost estimations presented in this study.

Based on the obtained results, it may be concluded that there was statistically significant difference in cost of materials between the types of cavities and teeth. The observation of a small difference in the values of the different resins evaluated revealed no significant differences in the final costs. This present study showed values of direct and indirect materials to be used. These values can be used as parameters for the calculation of the dental care fees. Again, the lack of other studies on the same subject makes it difficult to compare these results. This fact can be considered as one of the limitations of this type of study. In addition, other factors to be considered are the possible regional differences in the values of the presented materials. However, the methodology described in this present study, as well as the weight of composite resin increments can be easily reproduced in other studies, allowing the comparison of the present results.

Future studies should be conducted to evaluate the costbenefit ratio from the studied resins, as well as to compare the costs found in this present study with other costs in different regions and countries.

\section{References}

1. Mackenzie L, Parmar D, Shortall AC, Burke FJ. Direct anterior composites: a practical guide. Dent Update. 2013; 40: 297-9.

2. Wilson NH, Dunne SM, Gainsford ID. Current materials and techniques for direct restorations in posterior teeth. Part 2: resin composite systems. Int Dent J. 1997; 47: 185-93.

3. Drummond F. Methods for the economic evaluation of health care programmes. New York: Oxford; 2005. 379 p.

4. Shim JK, Siegel JG. Modern cost management and analysis. 3rd ed. New York: Barron's Education Series; 2009. 376 p.

5. Creese AL, Packer D. Cost analysis in primary health care: a training manual for programme managers. Geneva: World Health Organization; 1994. $147 p$

6. Gapenski LC. Healthcare Finance: An Introduction to Accounting and Financial Management. 5th ed. Portland: Health Administration Press; $2011.724 p$ 
7. Logan EM. Dentistry's business secrets: proven growth strategies for your new or existing practice. Bloomington: Authorhouse; 2011. $439 \mathrm{p}$.

8. Donaldson C. Economic evaluation in dentistry: an ethical imperative? Dent Update. 1998; 25: 260-4.

9. Bader J, Ismali A, Clarkson J. Evidence-based dentistry and the dental research community. J Dent Res. 1999; 78: 1480-3.

10. Smales RJ, Hawthorne WS. Long-term survival and cost-effectiveness of five dental restorative materials used in various classes of cavity preparations. Int Dent J. 1996; 46: 126-30.

11. Mjor IA, Burke FJ et al. The relative cost of different restorations in the UK. Br Dent J. 1997; 182: 286-9.

12. Miller $\mathrm{CH}$, Palenik CJ. Infection control and management of hazardous materials for the dental team. Saint Louis: Mosby; 2010.365 p.

13. Bonehill JA. Managing health and safety in the dental practice: a practical guide. Ames, lowa: Wiley-Blackwell; 2010. 264 p.

14. Lemay CA, Cashman SB, McDonald A, Graves JR. A new approach to ensuring oral health care for people living with HIVIAIDS: the dental case manager. Prev Chronic Dis. 2012; 9: E158.

15. Thomas MV, Jarboe G, Frazer RQ. Infection control in the dental office. Dent Clin North Am. 2008; 52: 609-28.

16. Dalli M, Çolak H, Mustafa Hamidi M. Minimal intervention concept: a new paradigm for operative dentistry. J Investig Clin Dent. 2012; 3: 167-75.

17. Robinson S, Nixon PJ, Gahan MJ, Chan MF. Techniques for restoring worn anterior teeth with direct composite resin. Dent Update. 2008; 35: 551-2.

18. Marinozzi S, Corbellini G, Ottolenghi L, Ripari F, Pizzuti A, Pezzetti M, et al. From Nuremberg to bioethics: an educational project for students of dentistry and dental prosthesis. Ann Stomatol. 2013; 4: 138-41.

19. Likert R. A Technique for the measurement of attitudes. Arch Psychol. 1932; 140: 1-55.

20. Siegel SC, Von Fraunhofer JA. Dental burs: what bur for which application? A survey of dental schools. J Prosthodont. 1999; 8: 258-63.

21. Siegel SC, Von Fraunhofer JA. Assessing the cutting efficiency of dental diamond burs. J Am Dent Assoc. 1996; 127: 763-72.

22. Gureckis KM, Burgess JO, Schwartz RS. Cutting effectiveness of diamond instruments subjected to cyclic sterilization methods. J Prosthet Dent. 1991; 66: 721-6.

23. Hebling $E$, Trentin EF. Cost analysis of materials used in composite resin direct posterior dental restorations. Rev Odontol UNESP. 2013; 42: 144-51.

24. Brazil. Brazilian Dentistry Council. Reference values for dental procedures. Brasília: Brazilian Dentistry Council; 2012.

25. Brazil. Health Ministry. [Operational Guidelines: pacts by life, in defense of the SUS and management]. 2nd ed. Brasilia: Health Ministry; 2006. Portuguese. 